\title{
Climate-friendly Construction and Renovation is the Key Task of the Building Sciences in this Century
}

\author{
Peter Häupl* \\ University of Technology, Germany
}

*Corresponding author: Peter Häupl, University of Technology, Germany

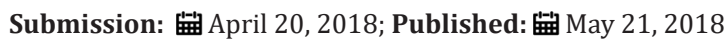

\section{Opinion}

At first we have to target an optimal internal space climate by a minimum of energy demand and a minimum of building services and equipment respectively

By means of a practicable model the hourly values of indoor air temperature and humidity in relation to the external climate, the building parameters (geometry, thermohygric material parameters), the ventilation and the use of the internal space (heat and moisture sources and interior heating system). Three hourly energy- and moisture balances are the key part of the model. The first two equations contain the storage of energy and moisture on the outside surface of the building by climatic loading. Secondly the energy and moisture transport by conduction, radiation and ventilation through the structure and windows has been quantified. In the third place the storage of energy and moisture on the inner surface and furnishing are to formulate. The results from the source text for the user-friendly Windows program CLIMT (CLimateIndoor-Moisture-Temperature). The results are validated e.g. in the German buildings “Golden hall” in Nürnberg” (2015, Figure 1-5), an floated house in Brandenburg (2008) and an new archive building in Magdeburg (2012). The calculated and measured results in the current state agree very well. Moreover the temperature course has been calculated also with the TRNSYS program. However the moisture tool in TRNSYS is physical incorrect and therefore it has not been used. In order to generate the outdoor climatic dates (hourly values of the temperature, relative humidity, short wave direct and diffuse radiation on chosen freely surfaces, long wave radiation, balance, precipitation, wind velocity, wind direction, driving rain on vertical surfaces) for the simulation of the room climate and the hygrothermic behaviour of building parts a climate generator CLIG has been developed additionally. It is possible with a minimum on equipment the monument Golden hall to open for visitors.

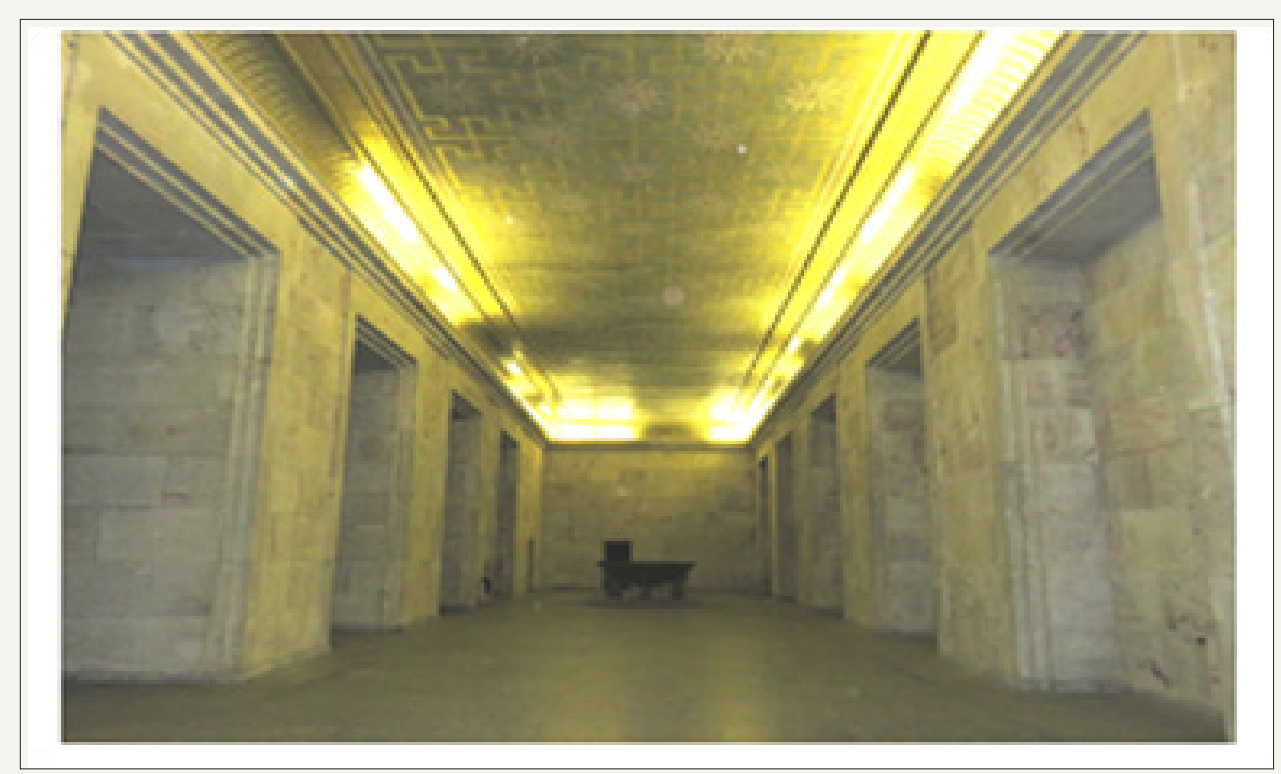

Figure 1: Golden hall below the Zeppelin terrace in Nürnberg. 


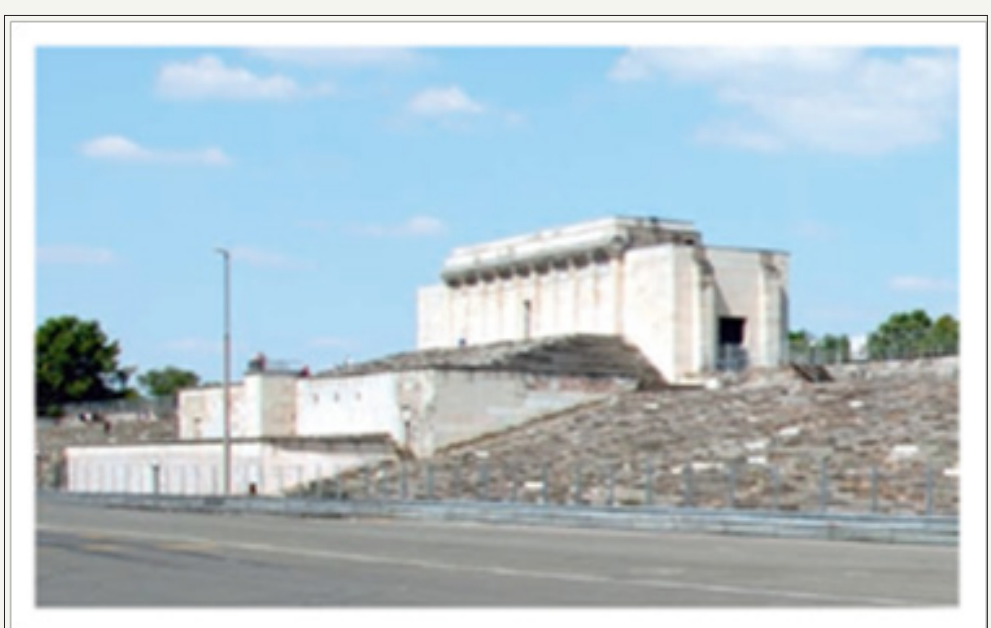

Figure 2: Ruin of the Zeppelintribüne Nürnberg.

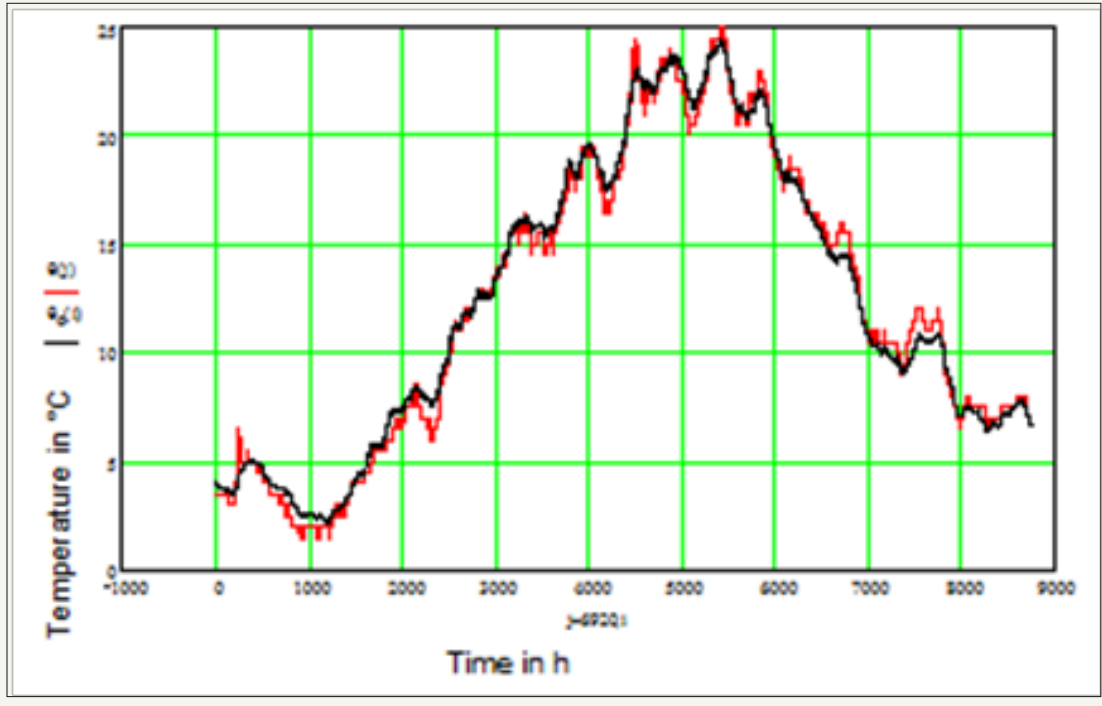

Figure 3: Indoor air temperature in 2015, measured (red), calculated by CLIMT (black).

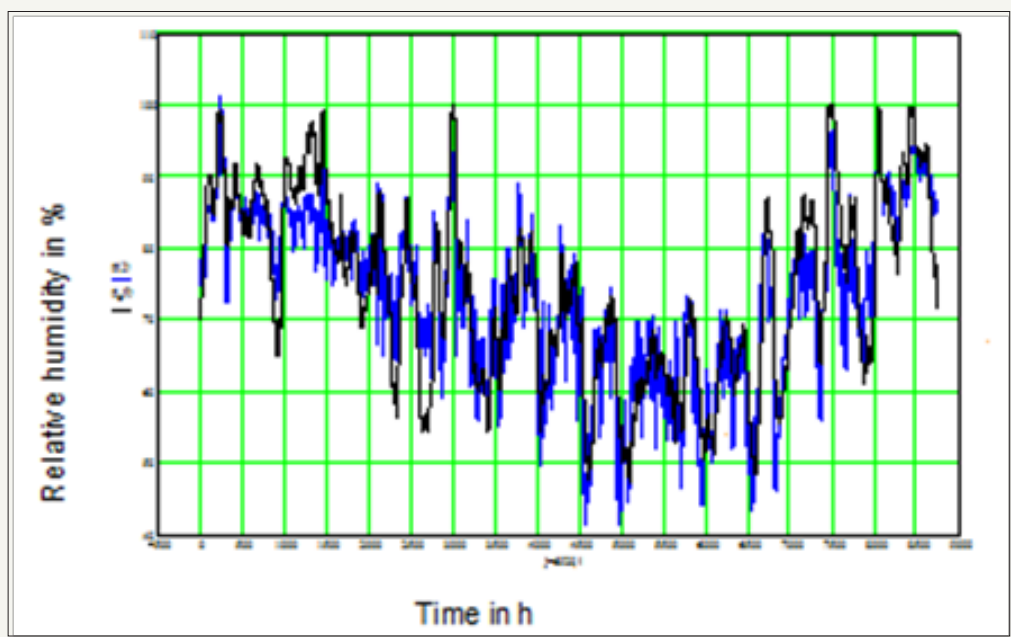

Figure 4: Indoor air relative humidity in 2015, measured (blue), by CLIMT (black). 


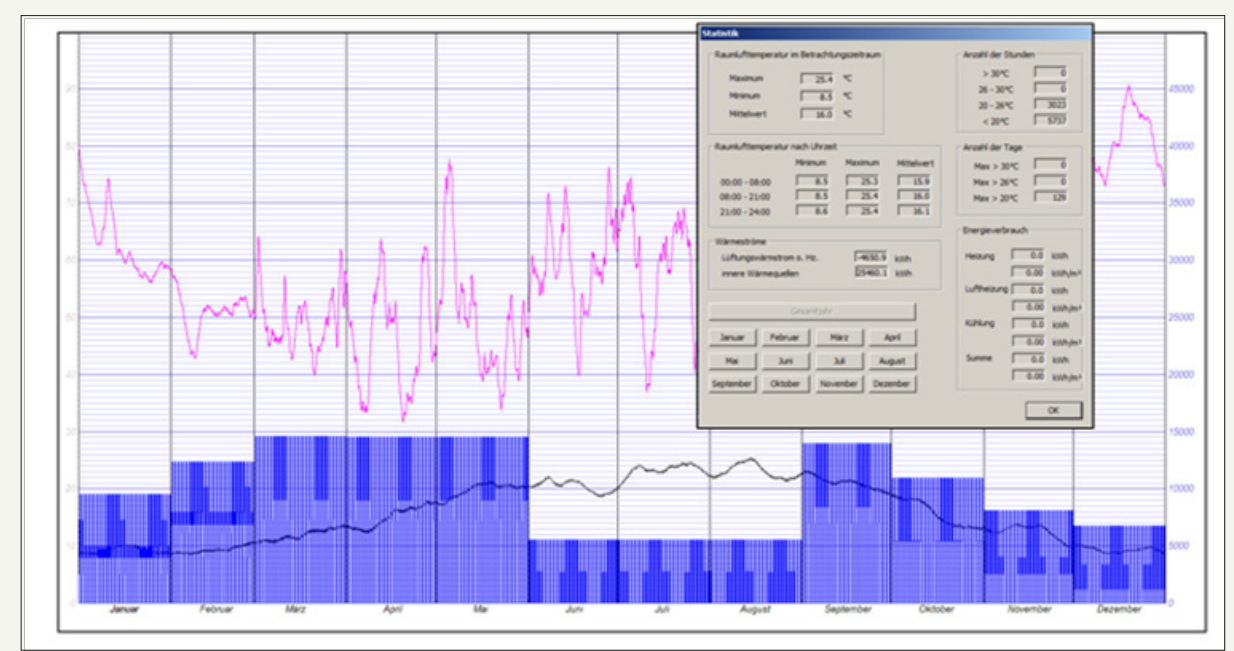

Figure 5: Indoor climate in the Golden hall in Nürnberg under condition of use prognosticated by CLIMT, proposal for a revitalisation of this monument.

Relative humidity in\% (magenda), temperature in ${ }^{\circ} \mathrm{C}$ (black), left coordinate axis, maximum temperature $25.4{ }^{\circ} \mathrm{C}$, minimum temperature $8.6^{\circ} \mathrm{C}$ and outdoor climate Nürnberg 2015. Conditions of use: 40 people a $100 \mathrm{~W}$ for four times one hour daily, light intensity during this time $1600 \mathrm{~W}$, photovoltaic heating system (monthly mean value as step function, active only during the day, excluding June to August), additional electrical heating power from $9 \mathrm{am}$ to $6 \mathrm{pm}$ by day (January $6 \mathrm{~kW}$,February $4 \mathrm{~kW}$ ) and from $3 \mathrm{am}$ to 9 am by night. (January and February $3 \mathrm{~kW}$ ), (blue), right coordinate axis, whole additional electrical heating energy only $3336 \mathrm{Wh}$., ventilation rate November to February $0.05 / \mathrm{h}$, March to October $0.2 \mathrm{~h} / \mathrm{h}$. The mask shows the termic threshold values for 2015

\section{Secondly we have to serve the durability of the structures in frame of the building and renovation}

For this goal a model fort the coupled heat-, moisture-, saltand air transfer in porous building materials and building parts has been developed.. By means of this model and the associated program DELPHIN the temperature fields and moisture behaviour (it serves as the basis fort the durability) of the structures can be calculated.

The example (Figure 6-9, Gründerzeithaus in Dresden, Germany, regular using by inhabitants, measured outdoor climate from 1996 to 2004 nearby the building) show the impact of an additional capillary active inside insulation. The thermal resistance will be duplicated The whole moisture content behind the insulation layer can be reduced on a quarter part compared with materials without capillary conductivity. Up to now unsatisfactory is the knowlegde of the moisture transport and storage functions, because this material functions are depending not only on the thermodynamic potentials but also on the thermodynamic processes. For important buildings (sandstone cupola of the Church of our Lady in Dresden, Rijksmuseum in Amsterdam, Humayun Tomb in New Delhi) the author has developed concepts for the durability of the structures in frame of the renovation.

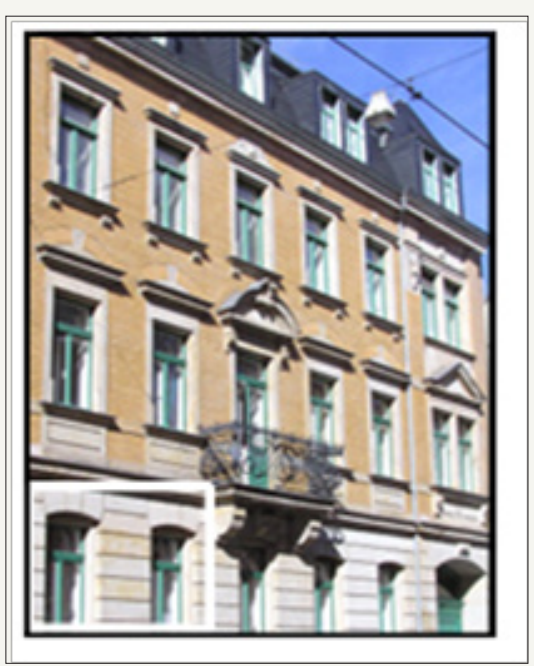

Figure 6: Gründerzeithaus in Dresden, energetical renovation of the wall in view. 


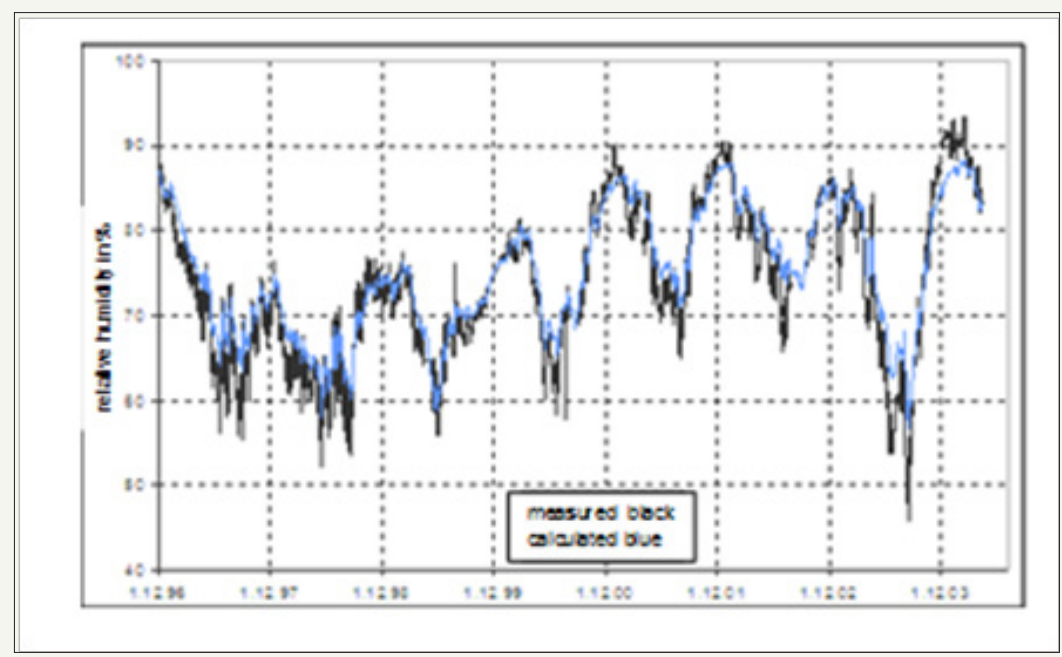

Figure 7: Relative humidity behind the inner insulation layer (from 1997 to 2004).

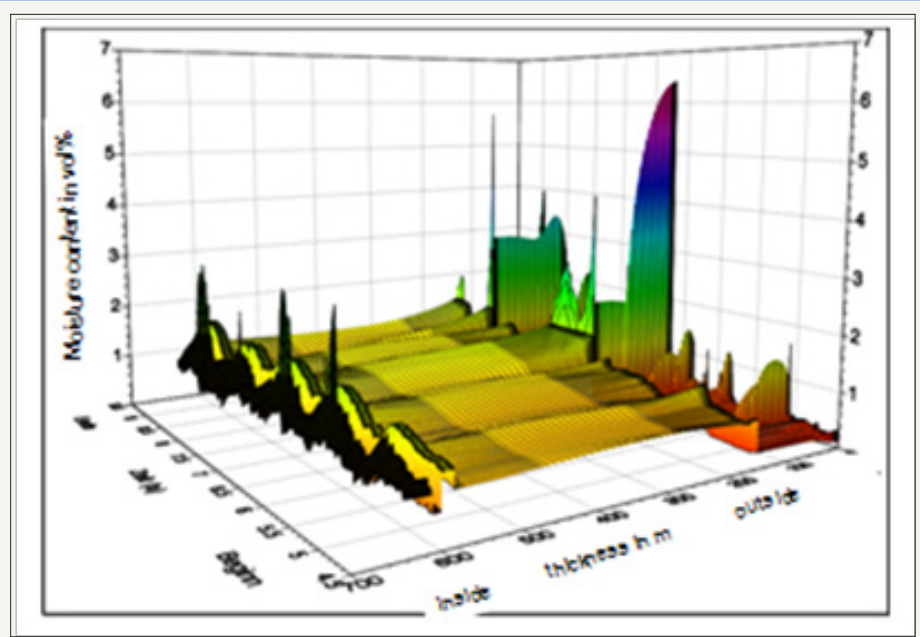

Figure 8: Moisture field in the wall with capillary active inside insulation (left hand side) from 1999 to 2004 , maximum moisture content $3 \mathrm{vol} \%$, moisture peaks on the outside (right hand side) are caused by driving rain.

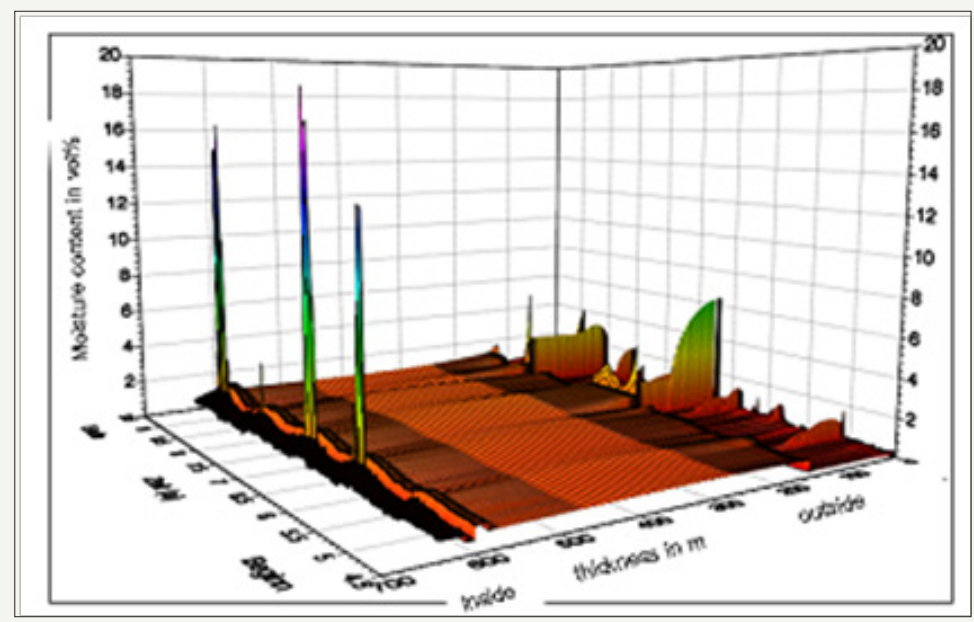

Figure 9: Moisture field in the wall with capillary non active inside insulation (left hand side) from 1999 to 2004, maximum moisture content $18 \mathrm{vol} \%$, moisture peaks on the outside (right hand side) are caused by driving rain. 


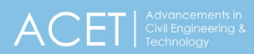

cc) International License

For possible submissions Click Here
Advancements in Civil Engineering \& Technology

\section{Benefits of Publishing with us}

- High-level peer review and editorial services

- Freely accessible online immediately upon publication

- Authors retain the copyright to their work

- Licensing it under a Creative Commons license

- Visibility through different online platforms 